\title{
The developmental fate of androgenetic, parthenogenetic, and gynogenetic cells in chimeric gastrulating mouse embryos
}

\author{
James Alexander Thomson and Davor Solter \\ The Wistar Institute, Philadelphia, Pennsylvania 19104 USA
}

\begin{abstract}
Both a maternal and a paternal genomic contribution are necessary for completion of embryonic development in the mouse. Parthenogenetic embryos, with only a maternally inherited genome, and androgenetic embryos, with only a paternally inherited genome, fail to develop to term, and these two types of isoparental embryos fail in development in characteristic ways. In this paper we describe the construction of chimeras between single androgenetic, parthenogenetic, and gynogenetic blastomeres and normal eight-cell embryos. We allow the development of the chimeras to reach the late-gastrulating-stage embryo and then analyze the tissue distributions of the isoparental component. The isoparental embryos are derived from a transgenic mouse line carrying plasmid and mouse $\beta$-globin sequences. The isoparental cells are detected in histological sections of chimeras by DNA-DNA in situ hybridization to the transgene, using a biotinylated DNA probe with an enzymatic detection system. We found strong tissue preferences for the androgenetic, parthenogenetic, and gynogenetic cells in chimeras. Androgenetic cells contributed strongly to all trophectoderm-derived tissue, with only a rare contribution to any tissues of the embryo proper, extraembryonic mesoderm, or extraembryonic endoderm. Parthenogenetic cells shared a developmental fate similar to gynogenetic cells, contributing to all tissues of the embryo proper and to the extraembryonic mesoderm, but only rarely to the extraembryonic endoderm or to any trophectoderm-derived tissues.
\end{abstract}

[Key Words: Androgenetic; parthenogenetic; gynogenetic; chimera; in situ hybridization; biotinylated]

Received April 21, 1988; revised version accepted July 21, 1988.

Recent evidence has suggested that in the mouse embryo, the genome inherited from the male parent functions differently from the genome inherited from the female parent. A reliable nuclear transfer technique (McGrath and Solter 1983) allows the construction of zygotes with two male pronuclei (androgenones) or two female pronuclei (gynogenones), and neither of these isoparental embryos develops to term (Barton et al. 1984; McGrath and Solter 1984; Surani et al. 1984). Parthenogenetically activated oocytes are capable of development to as far as the 25 -somite stage, but none develops to term and most die shortly after implantation (Kaufman et al. 1977).

The nuclear transfer studies provided evidence for imprinting of the genome during gametogenesis (McGrath and Solter 1984; Surani et al. 1984), so that both maternal and paternal genomes are required for normal development. Because the transferred genome was accompanied by nuclear proteins, nuclear membrane, and a small amount of cytoplasm during pronuclear transfer, it was still possible that nongenetic factors were responsible for the developmental differences observed in transferred male and female pronuclei. However, recent genetic studies have provided independent evidence for the nonequivalence of the parental genomes in the mouse (for review, see Cattanach 1986).

The mechanism of the developmental failure in parthenogenetic, androgenetic, and gynogenetic embryos is not known. In general, it is observed that parthenogenones (Kaufman et al. 1977) and gynogenones (Surani et al. 1984) have poorly developed extraembryonic membranes with a reasonably well-developed embryo proper, whereas androgenones exhibit a retarded embryonic component with well-developed extraembryonic membranes. (McGrath and Solter 1984; Surani et al. 1984).

To study further the developmental failure of isoparental embryos, we have made a series of chimeras between normal eight-cell embryos and single blastomeres from transgenic eight-cell normal, androgenetic, parthenogenetic, or gynogenetic embryos. Embryos were collected from a transgenic mouse line carrying plasmid and mouse $\beta$-globin sequences (strain 83; Lo 1986). Chimeras were allowed to develop to the gastrulating-stage embryo, and the transgenic component was detected by DNA-DNA in situ hybridization in histological sections using a biotinylated DNA probe and an enzymatic detection system. Using this marker system, we could detect individual isoparental cells in chimeras in situ 
without loss of histological information. Thus, we could examine in great detail the developmental potential of cells derived from androgenones, parthenogenones, or gynogenones to participate in the normal development of specific tissues in chimeric gastrulating embryos. We found that there were significantly different fates of androgenetic, parthenogenetic, and normal transgenic cells, and we found that gynogenetic cells shared a developmental fate similar to that of parthenogenetic cells in chimeras.

\section{Results}

\section{In situ technique}

In nontransgenic embryo sections, no hybridization signal was detected (Fig. 1A). In transgenic embryos, a high percentage of nuclei exhibited hybridization signal (Fig. 1B). As discussed previously, the percentage of nuclei exhibiting hybridization signal decreased with decreasing tissue section thickness and with increased nu-

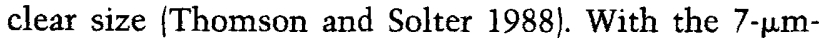
thick tissue sections used in this study, $90-95 \%$ of embryonic ectoderm nuclei of hemizygous transgenic embryos exhibited hybridization signals, although accurate counts were difficult to obtain because the nuclei overlap at this tissue thickness. In homozygous transgenic embryos, most nuclei ( $>75 \%$ ) exhibited two hybridization signals, whereas only one hybridization signal was usually present in the nuclei of hemizygous embryos. Rare $<5 \%$ of nuclei) cases of two hybridization signals in hemizygous nuclei probably resulted from overlapping nuclei that were difficult to distinguish. In every group of chimeras embedded and processed for in situ hybridization, a nonchimeric strain 83 transgenic embryo and a nonchimeric C57BL/6 embryo were included. Groups of chimeras that did not exhibit adequate hybridization signal on the nonchimeric transgenic control embryos were not analyzed.

\section{Control chimeras}

Table 1 shows the distribution of the transgenic component in gastrulating-stage chimeras made by injecting a single blastomere from an eight-cell homozygous transgenic embryo under the zona pellucida of an eight-cell C57BL/6 embryo (1/8 homozygous normal transgenic $+8 / 8 \mathrm{C} 57 \mathrm{BL} / 6$ chimeral and allowing it to develop for 7 days in foster mothers (day 9 of embryonic development). The developmental stage of the embryos dissected at day 9 of embryonic development was equivalent to a normal embryo of about day 7.5 of gestation, as the foster mothers were at day 0.5 of pseudopregnancy at the time of embryo transfer. Tissues labeled not present in Table 1 indicate that a particular chimera has not yet reached the stage where that tissue has developed. The visceral embryonic endoderm layer over the embryo at this stage is composed of a mixed population of cells derived from both the embryonic ectoderm and primitive endoderm (Lawson et al. 1986), and was designated in Table 1 simply as embryonic endoderm, with no attempt made to distinguish the components. Complete serial sections were examined for each chimera, and the percentage contribution to each tissue was assigned visually to the transgenic component, as shown in Table 1. For each tissue, some normal chimeras were recovered where there were substantial $(>50 \%)$ transgenic contributions, and there were no obvious tissue preferences, as the marked component was well distributed across the various tissues in different chimeras. Strict developmental neutrality of the transgenic marker was not addressed in our experiments. The presence of the homozygous transgene has no effect on the normal reproduction in strain 83 mice, but subtle effects of the marker in chimeras could still be possible. It is important to note that the normal transgenic cells were well represented in each tissue of the chimeric gastrulating embryo.

In the normal control chimera series (Table 1), $50 \%$ of
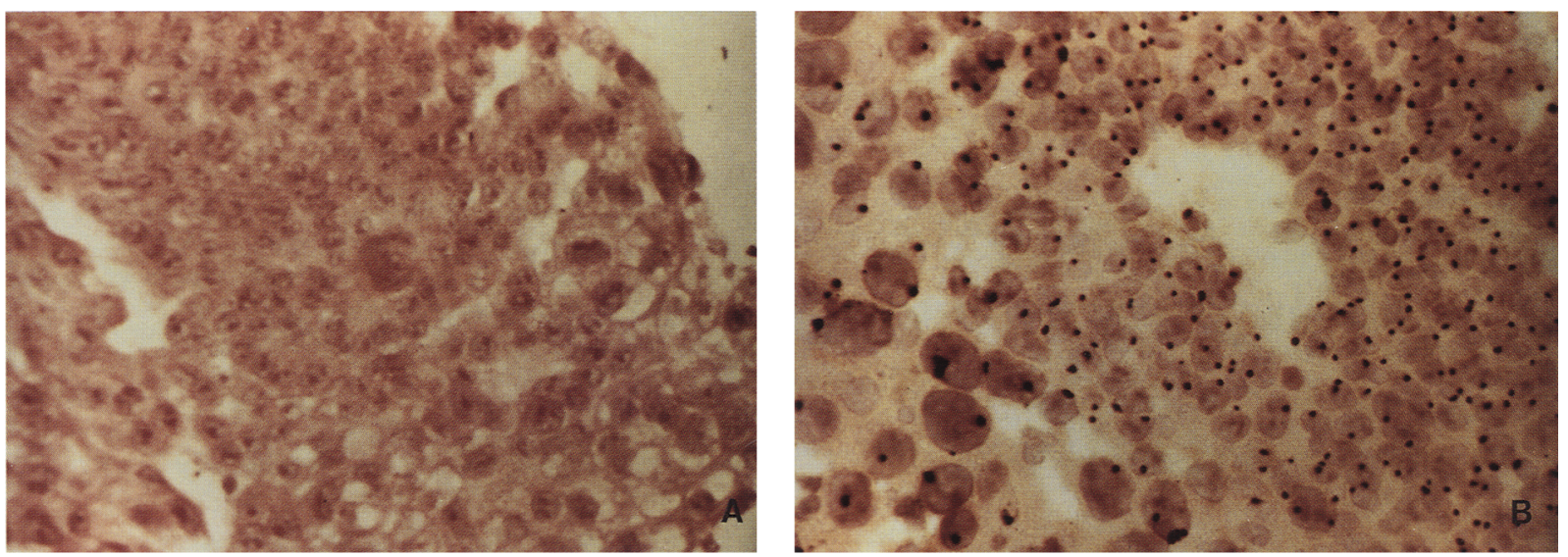

Figure 1. (A) C57BL/6 nontransgenic embryo; $(B)$ strain 83 hemizygous transgenic embryo. Both embryos were embedded, sectioned, mounted, and hybridized together on the same slide. The region shown in both embryos is the ectoplacental cone. Magnification, $162 \times$. 
Table 1. Normal control chimeras

\begin{tabular}{|c|c|c|c|c|c|c|c|c|c|c|}
\hline \multirow[b]{2}{*}{ Transgenic component } & \multicolumn{10}{|c|}{ Chimera } \\
\hline & 1 & 2 & 3 & 4 & 5 & 6 & 7 & 8 & 9 & 10 \\
\hline \multicolumn{11}{|l|}{ Trophoblast derived } \\
\hline Trophoblast giant cells & +++ & +++ & +++ & +++ & ++ & + & + & - & - & - \\
\hline Ectoplacental cone & +++ & +++ & +++ & +++ & + & + & + & - & - & - \\
\hline $\begin{array}{l}\text { Extraembryonic ectoderm } \\
\text { (includes chorion) }\end{array}$ & +++ & ++ & ++ & +++ & - & + & - & - & - & - \\
\hline \multicolumn{11}{|l|}{ Inner cell mass derived } \\
\hline $\begin{array}{l}\text { Visceral endoderm } \\
\text { (extraembryonic) }\end{array}$ & - & - & - & - & ++ & ++++ & ++++ & +++ & ++ & - \\
\hline Parietal endoderm & - & - & - & - & + & $+++t$ & +++ & +++ & + & - \\
\hline Embryonic endoderm & - & - & - & - & ++ & $++t+$ & $++t+$ & + & ++ & ++ \\
\hline Embryonic ectoderm & - & - & - & + & ++ & $++t$ & $++t+$ & + & +++ & $++t$ \\
\hline Embryonic mesoderm & - & - & - & + & ++ & $+t+t$ & $+t+t$ & + & $++t$ & $+t+$ \\
\hline Allantois & $\mathrm{np}$ & - & - & - & + & np & $+t+t$ & + & ++ & +++ \\
\hline Amnion (ectoderm) & np & - & - & ++ & + & $++t+$ & $++t$ & + & ++ & $+t+$ \\
\hline Amnion (mesoderm) & $\mathrm{np}$ & - & - & + & + & ++++ & +++ & + & +++ & $+t+$ \\
\hline Chorion (mesoderm) & $\mathrm{np}$ & - & - & - & ++ & $n p$ & $++t+$ & + & +++ & ++ \\
\hline
\end{tabular}

Distribution of the transgenic component in chimeric (1/8 normal transgenic $+8 / 8 \mathrm{C} 57 \mathrm{BL} / 6)$ gastrulating embryos. $(-)$ No contribution; $|+| 0-25 \% ;|++| 25-50 \% ;|+++| 50-75 \% ;|++++| 75-100 \%$. (np) Tissue not present.

embryos recovered from foster mothers demonstrated chimerism (see Table 5). This rate is comparable to that obtained in a previous study in which chimeras were constructed by injecting single blastomeres from 16-cell embryos under the zona pellucida of eight-cell embryos, where a rate of chimerism of $43 \%$ was obtained (Rossant and Vijh 1980). Transfer of androgenetic, parthenogenetic, and gynogenetic blastomeres resulted in a lower rate of chimerism (number of chimeras per embryo recovered) than transfer of normal blastomeres (see Table 5).

\section{Experimental chimeras}

Only correct identification of pronuclei during nuclear transfer resulted in the production of embryos homozygous for the transgenic marker (see Materials and methods), which was confirmed by the presence of two hybridization signals in a majority of labeled nuclei. Mistakes in the identification of pronuclei that resulted in the production of chimeras ( 1 of 8 hemizygous normal transgenic +8 of $8 \mathrm{C} 57 \mathrm{BL} / 6$ ) had only one hybridization signal per labeled nucleus. There was no obvious tissue preference for the hemizygous transgenic component in these chimeras, suggesting that the nuclear transfer technique itself does not alter developmental fate (data not shown\}.

Androgenetic cells in chimeras exhibited strong tissue preferences (Fig. 2A; Table 2). Androgenetic cells contributed strongly to trophoblast-derived tissues but not to inner-cell-mass-derived tissues. In a total of 10 androgenetic chimeras, there was only 1 with an androgenetic contribution to visceral or parietal endoderm (compared to 5 of 10 chimeras in controls). Also, there was only 1 chimera with an androgenetic contribution to embryonic ectoderm or embryonic mesoderm (compared to 7 of 10 chimeras in controls). In both of these exceptions, the chimera was in an earlier developmental stage than the other chimeras in the androgenetic group, not yet having an allantois, an amnion, or a fully formed chorion. We found no examples of androgenetic contributions to the other extraembryonic tissues derived from the inner cell mass (allantois, amnion, or mesodermal component of chorion).

Cells originating from parthenogenetic blastomeres were observed almost exclusively in the inner-cellmass-derived component of the conceptus and were generally absent from trophectoderm-derived tissues (Fig. $2 \mathrm{~B}$; Table 3). In only 1 chimera was there a parthenogenetic contribution to the trophoblastic giant cells, the ectoplacental cone, or extraembryonic ectoderm (compared to 7 of 10 in controls), and it was a minor contribution. In addition, parthenogenetic cells were poorly represented in extraembryonic visceral or parietal endoderm. Although 2 out of 10 chimeras had a parthenogenetic component in extraembryonic endoderm (compared to 5 of 10 in controls), in both of these chimeras, the parthenogenetic contribution to the extraembryonic endoderm was very small $(<5 \%)$. Parthenogenetic cells contributed strongly to embryonic ectoderm, embryonic mesoderm, embryonic endoderm, allantois, amnion, and mesodermal component of the chorion.

Gynogenetic cells in chimeras shared a fate similar to parthenogenetic cells (Fig. 2C; Table 4). Cells derived from gynogenetic blastomeres never contributed to trophoblast-derived tissues ( 0 of 5 chimeras), and the only gynogenetic contribution to the extraembryonic endoderm was a minor $(<5 \%)$ contribution in one chimera. Gynogenetic cells contributed strongly to embryonic ectoderm, embryonic mesoderm, embryonic endoderm, allantois, amnion, and mesodermal component of the chorion. 

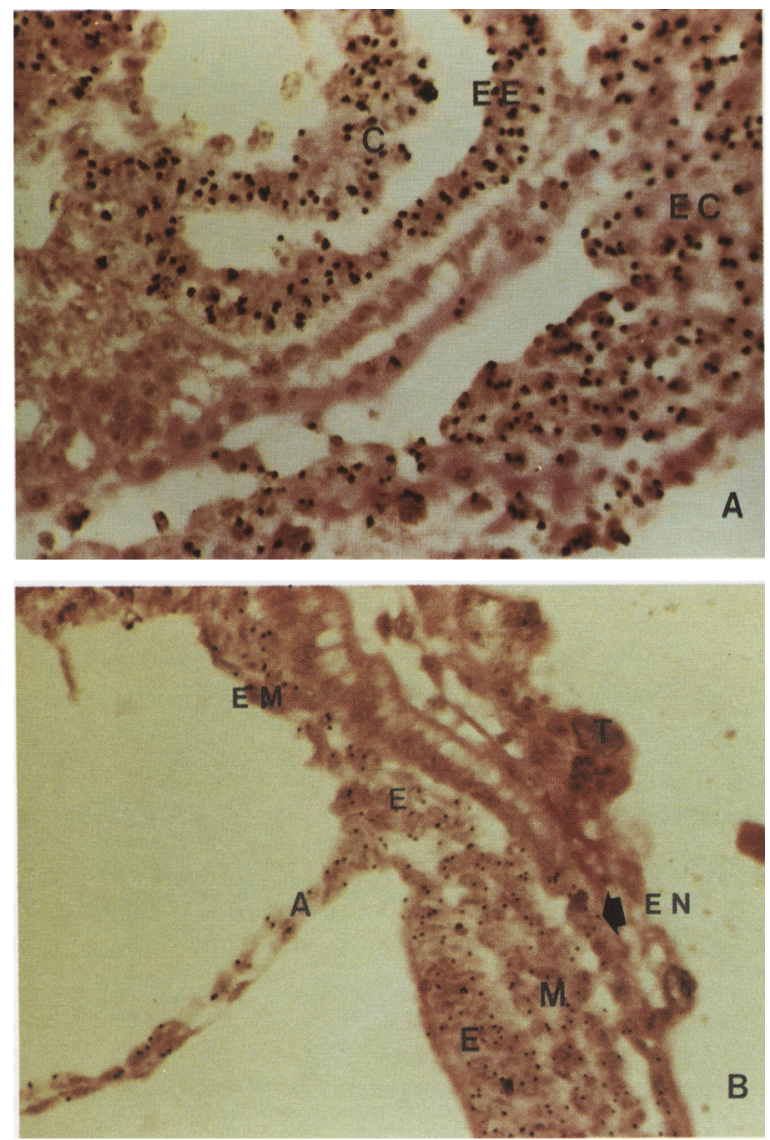

\section{Discussion}

We had two main reasons for constructing $1 / 8+8 / 8$ chimeras instead of the more common aggregation chimeras. First, aggregation chimeras must be cultured to

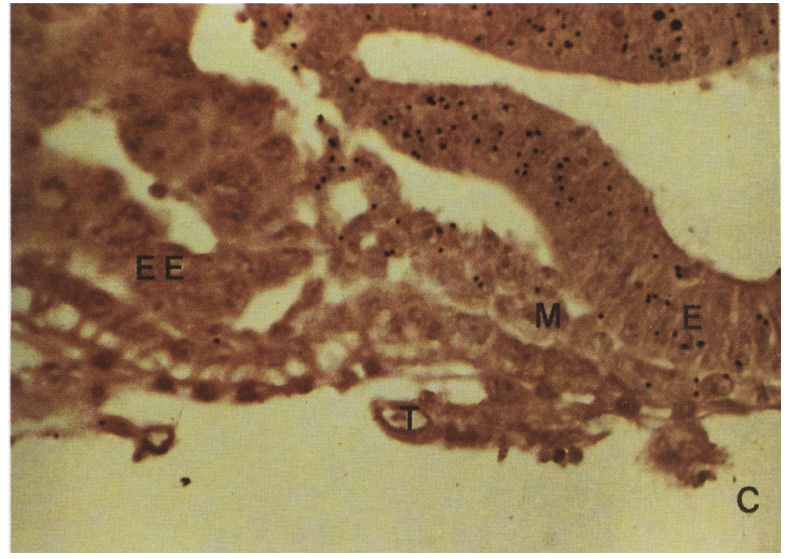

Figure 2. (A) $1 / 8$ androgenetic transgenic $+8 / 8 \mathrm{C} 57 \mathrm{BL} / 6 \mathrm{chi}-$ mera; $(B) 1 / 8$ parthenogenetic transgenic $+8 / 8 \mathrm{C} 57 \mathrm{BL} / 6 \mathrm{chi}-$ mera; $(C) 1 / 8$ gynogenetic transgenic $+8 / 8 \mathrm{C} 57 \mathrm{BL} / 6$ chimera. (A) amnion; (C) chorion; (E) embryonic ectoderm; (EC) ectoplacental cone; (EE) extraembryonic ectoderm; (EN) embryonic endoderm; $(\mathrm{M})$ embryonic mesoderm; $\{\mathrm{T}\rangle$ trophoblastic giant cell. All magnification, $162 \times$.

the blastocyst stage before being reintroduced to foster mothers, because the zonae pellucidae of the embryos are removed. With the blastomere transfer technique we used, the zona pellucida is left intact, and embryos can

Table 2. Androgenetic chimeras

\begin{tabular}{|c|c|c|c|c|c|c|c|c|c|c|}
\hline \multirow[b]{2}{*}{ Transgenic component } & \multicolumn{10}{|c|}{ Chimera } \\
\hline & 1 & 2 & 3 & 4 & 5 & 6 & 7 & 8 & 9 & 10 \\
\hline \multicolumn{11}{|l|}{ Trophoblast derived } \\
\hline Trophoblast giant cells & ++ & +++ & + & + & - & + & - & + & - & - \\
\hline Ectoplacental cone & $++t$ & +++ & + & ++ & ++ & ++ & + & + & + & - \\
\hline $\begin{array}{l}\text { Extraembryonic ectoderm } \\
\text { (includes chorion) }\end{array}$ & +++ & $+t+$ & $+t+$ & ++ & - & ++ & + & - & - & - \\
\hline \multicolumn{11}{|l|}{ Inner cell mass derived } \\
\hline $\begin{array}{l}\text { Visceral endoderm } \\
\text { (extraembryonic) }\end{array}$ & - & - & - & - & - & - & - & - & - & ++++ \\
\hline Parietal endoderm & - & - & - & - & - & - & - & - & - & $+++t$ \\
\hline Embryonic endoderm & - & - & - & - & - & - & - & - & - & $++t$ \\
\hline Embryonic ectoderm & - & - & - & - & - & - & - & - & +++ & - \\
\hline Embryonic mesoderm & - & - & - & - & - & - & - & - & +++ & - \\
\hline Allantois & - & - & - & - & - & - & - & - & $\mathrm{np}$ & $\mathrm{np}$ \\
\hline Amnion (ectoderm) & - & - & - & - & - & - & - & - & $\mathrm{np}$ & $\mathrm{np}$ \\
\hline Amnion (mesoderm) & - & - & - & - & - & - & - & - & np & $\mathrm{np}$ \\
\hline Chorion (mesoderm) & - & - & - & - & - & - & - & - & $\mathrm{np}$ & np \\
\hline
\end{tabular}

Distribution of the transgenic component in chimeric $(1 / 8$ androgenetic transgenic $+8 / 8 \mathrm{C} 57 \mathrm{BL} / 6)$ gastrulating embryos. $(-\mid$ No contribution; $|+| 0-25 \% ;|++| 25-50 \% ;|+++| 50-75 \% ; 1++++\mid 75-100 \%$. (np) Tissue not present. 
Table 3. Parthenogenetic chimeras

\begin{tabular}{|c|c|c|c|c|c|c|c|c|c|c|}
\hline \multirow[b]{2}{*}{ Transgenic component } & \multicolumn{10}{|c|}{ Chimera } \\
\hline & 1 & 2 & 3 & 4 & 5 & 6 & 7 & 8 & 9 & 10 \\
\hline \multicolumn{11}{|l|}{ Trophoblast derived } \\
\hline Trophoblast giant cells & + & - & - & - & - & - & - & - & - & - \\
\hline Ectoplacental cone & + & - & - & - & - & - & - & - & - & - \\
\hline Extraembryonic ectoderm (includes chorion) & + & - & - & - & - & - & - & - & - & - \\
\hline \multicolumn{11}{|l|}{ Inner cell mass derived } \\
\hline Visceral endoderm (extraembryonic) & - & + & - & - & - & - & - & - & - & - \\
\hline Parietal endoderm & - & + & + & - & - & - & - & - & - & - \\
\hline Embryonic endoderm & + & $+t+$ & $+t+$ & + & + & + & + & + & ++ & ++ \\
\hline Embryonic ectoderm & + & $+t+$ & +++ & + & + & + & +++ & +++ & +++ & $++t$ \\
\hline Embryonic mesoderm & + & +++ & +++ & + & + & + & $++t$ & +++ & $++t$ & ++ \\
\hline Allantois & ++ & +++ & +++ & + & + & + & np & $\mathrm{np}$ & +++ & $\mathrm{np}$ \\
\hline Amnion (ectoderm) & ++ & ++++ & ++ & + & + & + & np & +++ & ++++ & $\mathrm{np}$ \\
\hline Amnion (mesoderm) & ++ & +++ & +++ & + & + & + & $\mathrm{np}$ & +++ & ++++ & np \\
\hline Chorion (mesoderm) & ++ & ++++ & +++ & $\mathrm{np}$ & + & + & $\mathrm{np}$ & ++ & ++ & $\mathrm{np}$ \\
\hline
\end{tabular}

Distribution of the transgenic component in chimeric (1/8 parthenogenetic transgenic $+8 / 8 \mathrm{C} 57 \mathrm{BL} / 6)$ gastrulating embryos. $(-1$ No contribution; $|+| 0-25 \% ;|++| 25-50 \% ;|+++| 50-75 \% ;|++++| 75-100 \%$. (np) Tissue not present.

be transferred immediately to foster mothers, thus avoiding prolonged culture. Second, we hoped that by introducing only a minor labeled component, any tissue-specific selection would be more noticeable. Unfortunately, the use of the blastomere transfer technique resulted in a rate of chimerism that was always $<100 \%$, even in control chimeras. Although there was variability in rates of chimerism among experiments, the transfer of isoparental blastomeres always resulted in a rate of chimerism lower than the transfer of normal blastomeres (Table 5). We do not know the reason for this low rate of chimerism, but it suggests that isoparental cells

Table 4. Gynogenetic chimeras

\begin{tabular}{|c|c|c|c|c|c|}
\hline \multirow[b]{2}{*}{ Transgenic component } & \multicolumn{5}{|c|}{ Chimera } \\
\hline & 1 & 2 & 3 & 4 & 5 \\
\hline \multicolumn{6}{|l|}{ Trophoblast derived } \\
\hline cells & - & - & - & - & - \\
\hline Ectoplacental cone & - & - & - & - & - \\
\hline $\begin{array}{l}\text { Extraembryonic ectoderm } \\
\text { (includes chorion) }\end{array}$ & - & - & - & - & - \\
\hline \multicolumn{6}{|l|}{ Inner cell mass derived } \\
\hline $\begin{array}{l}\text { Visceral endoderm } \\
\text { (extraembryonic) }\end{array}$ & + & - & - & - & - \\
\hline Parietal endoderm & + & - & - & - & \\
\hline Embryonic endoderm & + & + & - & - & ++ \\
\hline Embryonic ectoderm & + & + & ++ & ++ & ++ \\
\hline Embryonic mesoderm & ++ & + & ++ & ++ & ++ \\
\hline Allantois & ++ & ++ & $\mathrm{np}$ & $\mathrm{np}$ & +++ \\
\hline Amnion (ectoderm) & ++ & + & $\mathrm{np}$ & np & ++++ \\
\hline Amnion (mesoderm) & ++ & + & np & np & +++ \\
\hline Chorion (mesoderm) & $\mathrm{np}$ & + & $\mathrm{np}$ & np & +++ \\
\hline
\end{tabular}

Distribution of the transgenic component in chimeric $11 / 8$ gynogenetic transgenic $+8 / 8 \mathrm{C} 57 \mathrm{BL} / 6)$ gastrulating embryos. $(-)$ No contribution; $1+\mid 0-25 \% ;(++) 25-50 \% ;(+++)$ $50-75 \% ;(++++\mid 75-100 \%$. (np) Tissue not present. have defects that are not limited to a few specific tissues, or the rate of chimerism would be much higher.

The blastomeres of the eight-cell embryo are thought to be totipotent (Kelly 1977). The distribution of the transgenic component in our normal chimeras confirms that individual blastomeres from 8-cell embryos can contribute to both inner cell mass and trophectoderm derivatives ( 4 of 10 chimeras). However, in individual chimeras, the transgenic component was rarely evenly distributed across lineages, as we found a tendency for a majority of the transgenic component to contribute either to trophectoderm derivatives or to inner cell mass derivatives (Table 1). For each tissue present in the gastrulating embryo, there was more than one normal control chimera where there was a large $(>50 \%)$ transgenic component.

Previous studies have shown distinct tissue distributions for androgenetic and parthenogenetic cells in chimeras (Nagy et al. 1987; Surani et al. 1987). In chimeras between androgenetic and parthenogenetic embryos, at 10 days of gestation, androgenetic cells contributed primarily to trophoblast and yolk sac, and parthenogenetic cells contributed primarily to yolk sac and embryo (Surani et al. 1987). Also, in chimeras with normal embryos, parthenogenetic cells contributed to embryo and yolk sac (Surani et al. 1988), with a selection against the parthenogenetic cells in all tissues at later stages of development (Nagy et al. 1987). At 10 days of gestation in chimeras with normal cells, androgenetic cells contributed primarily to trophoblast and yolk sac (Surani et al. 1988). The isozyme markers used in these previous studies of chimeras restricted the analysis to a few tissues of embryos at midgestation or later.

In our studies, we found that differences in tissue distributions of androgenetic and parthenogenetic cells in chimeras are already present in gastrulating embryos. Because we used an in situ marker, we were able to separate tissues into their component cells types. Partheno- 
Table 5. Embryo implantation, recovery, and rate of chimerism

\begin{tabular}{lccrc}
\hline Chimera type & Transferred & Implanted & Embryos $^{\mathrm{a}}$ & Chimeras $^{\mathrm{b}}$ \\
\hline Normal & 175 & 94 & $40(23 \%)$ & $20(50 \%)$ \\
Androgenetic & 1332 & 616 & $279(21 \%)$ & $12(4.3 \%)$ \\
Parthenogenetic & 599 & 292 & $154(26 \%)$ & $12(7.8 \%)$ \\
Gynogenetic & 244 & 163 & $95(39 \%)$ & $5(5.7 \%)$ \\
\hline
\end{tabular}

a Percentage of embryos recovered of total embryos transferred.

b Percentage of chimeric embryos.

genetic cells contributed equally well to each tissue present in the gastrulating embryo derived from the inner cell mass, except for extraembryonic endoderm. Thus, in the yolk sac, we found that parthenogenetic cells contributed strongly to the mesodermal component but contributed poorly to the extraembryonic endodermal component. This apparent failure of the extraembryonic endoderm may account, in part, for the inability of parthenogenetic inner cell masses introduced into normal trophectoderm vesicles to support complete development (Barton et al. 1985). In androgenetic chimeras, we never saw a contribution to the mesodermal component of the yolk sac, and although we found only one example of a contribution to the extraembryonic endodermal component, it was a major contribution $(>75 \%)$. Androgenetic cells contributed equally well to all trophoblast-derived tissues present in the gastrulating embryo. In balanced aggregation chimeras between androgenones or parthenogenones and normal embryos at 10 days of gestation, Surani et al. (1988) found 4 out of 10 chimeras with some androgenetic contribution to the yolk sac, and 6 out of 14 chimeras with a minor parthenogenetic contribution to the trophectoderm. It is possible that our unbalanced $1 / 8+8 / 8$ chimeras allowed greater selection against the minor component and allowed more subtle developmental differences between androgenetic, parthenogenetic, and normal cells to be detected.

In the past, gynogenones have been assumed to be equivalent to diploid parthenogenones, because both have two maternally derived haploid genomes and both share similar phenotypes (Kaufman et al. 1977; Surani et al. 1984). To test their equivalence, we made a series of gynogenetic chimeras (Table 4) to see if the gynogenetic cells had the same developmental fate in chimeras as parthenogenetic cells. A comparison of Tables 3 and 4 suggests that gynogenones and parthenogenones are developmentally similar, as gynogenetic cells contributed strongly to embryonic ectoderm, embryonic mesoderm, embryonic endoderm, and extraembryonic mesoderm, but not to trophoblast derived tissues, and only once as a minor component to extraembryonic endoderm. It appears, then, that the female pronucleus and the second polar body are functionally identical, with the same maternal imprint.

Our experiments suggest that important functional differences between the maternal and paternal genomes exist early in development, because strong tissue-specific selection against the androgenetic or parthenogenetic components has already taken place in chimeras by late gastrulating stage. However, exceptions were one chimera with parthenogenetic cells contributing to trophectoderm derivatives, one chimera where androgenetic cells contributed to extraembryonic endoderm, and one chimera where androgenetic cells contributed to embryonic ectoderm and mesoderm. Both chimeras where androgenetic cells contributed to inner cell mass derivatives were retarded in development compared to other androgenetic chimeras, which is consistent with the androgenetic cells being functionally abnormal in those tissues.

Several possibilities exist to explain the observed distributions of isoparental components in chimeras. First, it is possible that selective embryo death is taking place. Isoparental cells may contribute to all tissues, but those chimeras that happen to have a large isoparental component to a specific tissue may die and not be represented when the embryos are dissected. A comparison of embryo recovery rates in Table 5 suggests that this is not the case, as these rates for the normal and isoparental chimeras are similar, although rate of embryo recovery and rate of chimerism are low and some selective embryo death might not be detectable. Second, it is possible that the isoparental cells simply do not allocate normally to specific tissues, so that they are simply not present from the beginning of a tissue's existence. Third, it is possible that isoparental cells allocate normally to specific tissues, but that either by cell death, by exclusion from the embryo, or by a failure to proliferate, they are no longer well represented in that tissue at the time the chimeras are dissected. These second and third general possibilities can be distinguished by looking at chimeras at the time of allocation of cell to specific tissues. We currently are studying the allocation of isoparental cells to inner cell mass and trophectoderm in chimeric blastocysts to help address this problem (J.A. Thomson and D. Solter, in prep.). Studying the rate of chimerism in blastocysts (number of chimeric blastocysts per micromanipulated embryo) will also establish whether the poor rate of chimerism observed for isoparental cells in the present study in gastrulating embryos (Table 5) is already present in the blastocyst or whether a general selection against the isoparental component occurs later. 


\section{Materials and methods}

\section{Animals}

Strain 83 mice are a transgenic line that have an insert of exogenously introduced DNA sequences of the mouse $\beta$-major globin gene and plasmid pBR322 (Lo 1986). The transgene is present at a copy number of $\sim 1000$, and there is no detectable expression. The transgene is stably transmitted to progeny and does not interfere with normal reproduction even when homozygous. Embryos for the nontransgenic component of all chimeras were obtained by C57BL/ $6 \times \mathrm{C} 57 \mathrm{BL} / 6$ matings. For zygotes to be used for the production of androgenones, male homozygous strain 83 mice were mated to nontransgenic C57BL/6 females, whereas for zygotes used for the production of gynogenones, male nontransgenic C57BL/6 mice were mated with homozygous strain 83 females. Homozygous strain 83 embryos were used in chimeras with normal C57BL/6 embryos for controls.

\section{Production of androgenones, gynogenones, and} parthenogenones

Three- to four-week-old C57BL/6 or homozygous strain 83 female mice were injected with 5 IU pregnant mare's serum gonadotropin (PMSG) and then $10 \mathrm{IU}$ human chorionic gonadotropin (hCG) $48 \mathrm{hr}$ later. These mice were mated with appropriate males (above) and checked for vaginal plugs the next morning (day of plug is designated day zero). Zygotes were collected, and androgenones and gynogenones were constructed by nuclear transfer, as described previously (McGrath and Solter 1983). Note that because of the mating strategy described above, correct identification of pronuclei during nuclear transfer resulted in the production of androgenones or gynogenones that were homozygous for the transgene. Misidentification of pronuclei resulted in the production of embryos that were either hemizygous or nontransgenic. Androgenones, gynogenones, and nontransgenic normal zygotes were cultured under oil at $37^{\circ} \mathrm{C}$ in modified Whitten's medium (MWM) with 4 $\mathrm{mg} / \mathrm{ml}$ bovine serum albumin (BSA) in an atmosphere of $5 \%$ $\mathrm{CO}_{2}, 5 \% \mathrm{O}_{2}$, and $90 \% \mathrm{~N}_{2}$ (Abramczuk et al. 1977) to the eightcell stage (day 2.5).

For the production of parthenogenetic embryos, homozygous strain 83 female mice were injected with 5 IU PMSG and then with $10 \mathrm{IU}$ hCG $48 \mathrm{hr}$ later. Cumulus mass-enclosed oocytes were collected $17 \mathrm{hr}$ after the injection of hCG. Cumulus cells were dispersed by incubation in $300 \mathrm{IU} / \mathrm{ml}$ hyaluronidase (bovine testes, Sigmal in MWM for $5 \mathrm{~min}$ at $37^{\circ} \mathrm{C}$. Oocytes were activated by incubation in MWM with 7\% ethanol for 5-6 min at room temperature, washed three times in medium, and cultured for $4 \mathrm{hr}$ in MWM containing $1 \mu \mathrm{g} / \mathrm{ml}$ of cytochalasin D (Sigma) to suppress second polar body extrusion (Cuthbertson 1983). Successfully activated diploid parthenogenetic embryos were selected, washed six times for $5 \mathrm{~min}$ each in medium, and cultured as above. The next morning, any four-cell or grossly abnormal embryos were discarded, and the remaining two-cell parthenogenetic embryos were cultured another day to the eight-cell stage.

\section{Production of chimeras}

Chimeras were constructed using a Leitz micromanipulator. The eight-cell transgenic embryos, whether androgenetic, gynogenetic, parthenogenetic, or normal control, were incubated in $0.5 \%$ Pronase (Sigma) in phosphate-buffered saline (PBS $=$ $0.13 \mathrm{M} \mathrm{NaCl}, 0.007 \mathrm{M} \mathrm{Na}_{2} \mathrm{HPO}_{4}, 0.003 \mathrm{M} \mathrm{NaH}_{2} \mathrm{PO}_{4}$ ) at $37^{\circ} \mathrm{C}$ for $5 \mathrm{~min}$ or less to remove the zona pellucida. A blastomere transfer pipette was made using the same technique described for nuclear transfer pipettes (McGrath and Solter 1983), except that the inside diameter was about 25-30 $\mu \mathrm{m}$. Embryos were incubated for $5 \mathrm{~min}$ in $1 \mu \mathrm{g} / \mathrm{ml}$ cytochalasin D in MWM prior to and during manipulation. Multiple transgenic blastomeres were drawn into the transfer pipette, and individual blastomeres were injected under the zona pellucida of nontransgenic eight-cell embryos (1/8 $+8 / 8$ chimeras). Manipulated embryos were washed four times for $5 \mathrm{~min}$ or more each in MWM and then transferred to the oviducts of day- 0.5 pseudopregnant CD-1 female mice (Charles River). Transfer to day-1.5 pseudopregnant female mice was not used because it resulted in significantly lower implantation rates than transfer to day- 0.5 pseudopregnant females (data not shown).

\section{Embryo fixation, embedding, and sectioning}

Foster mothers were killed 7 days after embryo transfer. The embryos were dissected from the decidua, fixed in $3: 1$ ethanol/acetic acid for $1 \mathrm{hr}$; and transferred to absolute ethanol two times for $1 \mathrm{hr}$ each. From the ethanol, embryos were placed directly into ester wax (Gurr 1960 ester wax, Gallard-Schlessinger| at $50^{\circ} \mathrm{C}$ and impregnated overnight. For embedding, a $5 / 8 \times 5 / 8 \times 1 / 4$-inch metal base mold (Tissue-tek, Miles Laboratories/ was placed on a slide warmer set at $50^{\circ} \mathrm{C}$. A $1-\mathrm{mm}$ thick $2 \%$ agar block, impregnated with ester wax, was placed in the bottom of the base plate, and embryos were carefully positioned on top of this agar before filling up the rest of the block with wax. The agar block prevented any embryo sections from being lost at the beginning of sectioning. Embryos were sectioned to $7 \mu \mathrm{m}$, floated in a water bath onto polylysine-treated slides, and placed on a slide warmer at $45^{\circ} \mathrm{C}$ overnight. Slides were dewaxed in two changes of xylene, followed by two changes of absolute ethanol, and then air-dried.

\section{In situ hybridization}

The DNA probe used for in situ hybridization was plasmid pMBd2, consisting of plasmid pBR322 with an insert of $4.5 \mathrm{kbp}$ of mouse genomic DNA containing part of the $\beta$-major globin gene (Lo 1986). Plasmid pMBd2 was nick-translated using standard procedures (Rigby et al. 1977), replacing dTTP with biotinylated dUTP (16-mer, Enzo) in the reaction mixture. Final probe concentration for in situ hybridization was $0.5-1.0 \mu \mathrm{g} / \mathrm{ml}$. To denature the DNA in the tissue sections, slides were placed in $95 \%$ formamide, $0.1 \times$ SSC $(1 \times$ SSC $=0.15 \mathrm{M} \mathrm{NaCl}, 0.015 \mathrm{M}$ sodium citrate at $\mathrm{pH} 7.0$ ) at $70^{\circ} \mathrm{C}$ for $30 \mathrm{~min}$, plunged into icecold $70 \%$ ethanol for $5 \mathrm{~min}$, and dehydrated and air-dried. Hybridization was carried out in $1.3 \times \operatorname{SSCP}(0.16 \mathrm{M} \mathrm{NaCl}, 0.02 \mathrm{M}$ sodium citrate, $0.026 \mathrm{M}$ sodium phosphate at $\mathrm{pH} 6.0$ ) with $13.3 \%$ dextran sulfate in $30 \%$ formamide (Lo 1986). Fifty microliters of hybridization mixture was placed on each slide. The slides were then covered with a siliconized coverslip (Prosil, Thomas), sealed with rubber cement, and incubated at $37^{\circ} \mathrm{C}$ for 48-72 hr. After hybridization, the slides were washed three times, for $5 \mathrm{~min}$ each, in $30 \%$ formamide with $2 \times \mathrm{SSC}$ at $39^{\circ} \mathrm{C}$ and then washed three times, for $3 \mathrm{~min}$ each, in $2 \times \mathrm{SSC}$ at $39^{\circ} \mathrm{C}$.

\section{Signal detection}

A streptavidin-horseradish peroxidase (S-HRP) detection system (DETEK I-hrp, Enzo), combined with 3,3'-diaminobenzidine (DAB) silver enhancement (Amersham), was used for signal detection. Binding of the S-HRP complex to hybridized 
tissue sections was carried out largely as recommended by Enzo. Slides were blocked in PBS containing $0.1 \%$ Triton X-100 and $1 \% \mathrm{BSA}$ and washed for $5 \mathrm{~min}$ in PBS. Stock S-HRP $\mid 5.0 \mu l$ was diluted to $1.0 \mathrm{ml}$ with complex dilution buffer $(1 \times \mathrm{PBS}, 5$ mM EDTA, 1\% BSA), and $100 \mu \mathrm{l}$ of this solution was added to each slide. The slides were covered with siliconized coverslips and incubated at $37^{\circ} \mathrm{C}$ for $1-2 \mathrm{hr}$ in a humidified chamber. The slides were then washed four times for 5 min each in washing buffer (10 $\mathrm{mM} \mathrm{KPO}_{4}$ at $\mathrm{pH} 6.5,0.5 \mathrm{M} \mathrm{NaCl}, 1 \mathrm{mM}$ EDTA, $0.5 \%$ Triton X-100, $0.1 \% \mathrm{BSA}$ ) and placed in PBS for $5 \mathrm{~min}$.

The enzyme reaction and subsequent silver enhancement were carried out exactly as described in the Amersham kit. Best results were obtained with a $2.5-\mathrm{min}$ incubation in the $\mathrm{DAB}$, and a $7-\mathrm{min}$ incubation in the silver reagent. After completion of the silver amplification procedure, the sections were stained with hematoxylin and eosin.

\section{Acknowledgments}

We thank Cecilia Lo for providing the strain 83 transgenic mice and the plasmid and for help with the in situ hybridization. Janet Rossant contributed many helpful suggestions to the in situ hybridization procedure. We also thank Elsa Aglow for sectioning the chimeras. This work was supported by grants HD-17720, HD-23291, and CA-10815 from the National Institutes of Health. J.T. is a participant in the Veterinary Medical Research Training Program at the University of Pennsylvania.

\section{References}

Abramczuk, J., D. Solter, and H. Koprowski. 1977. The beneficial effect of EDTA on development of mouse one-cell embryos in chemically defined medium. Dev. Biol. 61: 738783.

Barton, S.C., M.A. Surani, and M.L. Norris. 1984. Role of paternal and maternal genomes in mouse development. $\mathrm{Na}$ ture 311: 374-376.

Barton, S.C., C.A. Adams, M.L. Norris, and M.A. Surani. 1985. Development of gynogenetic and parthenogenetic inner cell mass and trophectoderm tissues in reconstituted blastocysts in the mouse. J. Embryol. Exp. Morphol. 90: 267-285.

Cattanach, B.M. 1986. Parental origin effects in mice. J. Embryol. Exp. Morphol. 97: 137-150.

Cuthbertson, K.S. 1983. Parthenogenetic activation of mouse oocytes in vitro with ethanol and benzyl alcohol. $J$. Exp. Zool. 226: $311-314$.

Kaufman, M.H., S.C. Barton, and M.A. Surani. 1977. Normal postimplantation development of mouse parthenogenetic embryos to the forelimb bud stage. Nature 265: 53-55.

Kelly, A. 1977 . Studies of the developmental potential of 4- and 8-cell stage mouse blastomeres. J. Exp. Zool. 200: 365-376.

Lawson, K.A., J.J. Meneses, and R.A. Pedersen. 1986. Cell fate and cell lineage in the endoderm of the presomite mouse embryo, studied with an intracellular tracer. Dev. Biol. 115: 325-339.

Lo, C.W. 1986. Localization of low abundance DNA sequences in tissue sections by in situ hybridization. I. Cell. Sci. 81: $143-162$.

McGrath, J. and D. Solter. 1983. Nuclear transplantation in the mouse embryo by microsurgery and cell fusion. Science 220: $1300-1303$.

- 1984. Completion of mouse embryogenesis requires both the maternal and paternal genomes. Cell 37: 179-183.

Nagy, A., A. Paldi, L. Dezso, L. Varga, and A. Magyar. 1987.
Prenatal fate of parthenogenetic cells in mouse aggregation chimeras. Development 101: 67-71.

Rigby, R.W., M. Dreckman, C. Rhodes, and P. Berg. 1977. Labelling deoxyribonucleic acid to high specific activity in vitro by nick translation with DNA polymerase. J. Mol. Biol. 113: $237-252$.

Rossant, J. and K.M. Vijh. 1980. Ability of outside cells from preimplantation mouse embryos to form inner cell mass derivatives. Dev. Biol. 76: 475-482.

Surani, M.A., S.C. Barton, and M.L. Norris. 1984. Development of reconstituted mouse eggs suggests imprinting of the genome during gametogenesis. Nature 308: $548-550$.

- 1987. Influence of parental chromosomes on spatial specificity in androgenetic $\leftrightarrow$ parthenogenetic chimaeras in the mouse. Nature 326: 395-397.

Surani, M.A., S.C. Barton, S.K. Howlett, and M. L. Norris. 1988. Influence of chromosomal determinants on development of androgenetic and parthenogenetic cells. Development 103: $171-178$.

Thomson, J.A. and D. Solter. 1988. Transgenic markers for mammalian chimeras. Wilhelm Roux's Arch. Dev. Biol. 197: 63-65. 


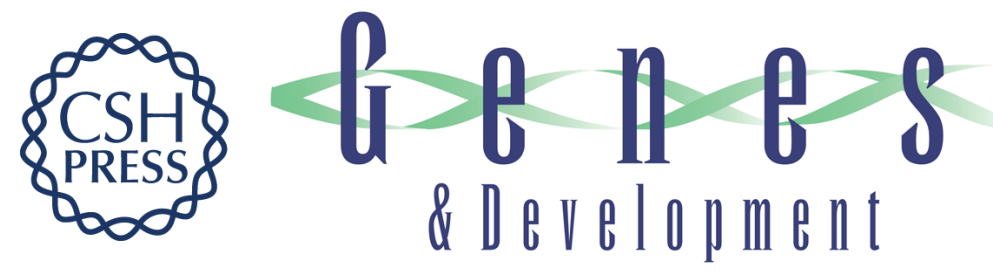

\section{The developmental fate of androgenetic, parthenogenetic, and gynogenetic cells in chimeric gastrulating mouse embryos.}

\section{J A Thomson and D Solter}

\section{Genes Dev. 1988, 2:}

Access the most recent version at doi:10.1101/gad.2.10.1344

References This article cites 18 articles, 4 of which can be accessed free at:

http://genesdev.cshlp.org/content/2/10/1344.full.html\#ref-list-1

License

Email Alerting

Service

Receive free email alerts when new articles cite this article - sign up in the box at the top right corner of the article or click here.

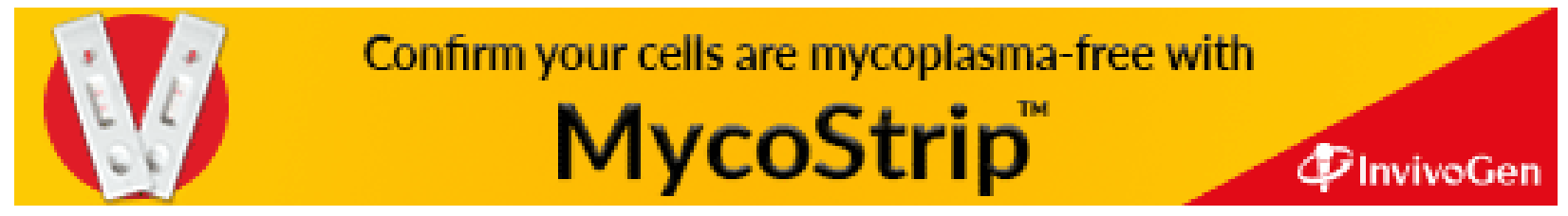

